\section{Transport of Cross-pollen by Bumblebees in a Rabbiteye Blueberry Planting}

\author{
Patricio A. Brevis ${ }^{1}$ \\ Department of Horticulture, Michigan State University, A316 Plant and Soil \\ Science Building, East Lansing, MI 48824-1325
}

\section{Scott NeSmith ${ }^{2}$ \\ Department of Horticulture, University of Georgia, Griffin Campus, Griffin, GA 30223}

Additional index words. Vaccinium ashei, Ericaceae, pollen dispersion, self-pollination, Bombus spp., tetrad diameter

\begin{abstract}
Rabbiteye blueberry (Vaccinium ashei Reade) is a bee-pollinated small fruit crop that often exhibits poor fruit set. Mixed cultivar plantings are recommended because crosspollination is required for optimum yields, and bees are expected to transfer pollen from one cultivar to another. The objective of this study was to assess transport of cross-pollen by bumblebees in a rabbiteye blueberry planting. Experiments were conducted in 2003 and 2004 in a plot composed of 'Brightwell' and 'Climax' plants arranged in alternating rows. The proportion of 'Brightwell' and 'Climax' pollen carried on the bodies of bumblebees was estimated based on frequency distributions of pollen diameter, measured with a particle counter. About $\mathbf{7 5 \%}$ of bumblebees collected in 2003 carried $<\mathbf{2 0} \%$ cross-pollen. Proportions of cross-pollen in 2004 were higher than in 2003, but still, about $85 \%$ of bumblebees collected carried $<\mathbf{4 0} \%$ cross-pollen. The proportion of cross-pollen carried by bumblebees changed during the flowering season. The greatest likelihood for cross-pollination occurred during the time of maximum bloom overlap, although the median proportion of cross-pollen was not $>30 \%$ on any sampling day of 2004 . The results from this study emphasize the need to select more self-fertile rabbiteye blueberry cultivars and to maximize bloom overlap in blueberry plantings.
\end{abstract}

The degree of self-fertility in many flowering plants is often limited by mechanisms such as prezygotic self-incompatibility and earlyacting inbreeding depression (Klekowski, 1988; De Nettancourt, 1977; Seavey and Bawa, 1986). Outcrossing is thus beneficial or even required in such species for fruit set and seed maturation. In blueberries (Vaccinium section Cyanococcus), cross-pollination normally results in higher fruit set, larger fruit size, and faster ripening rate relative to self-pollination (El-Agamy et al., 1981; Meader and Darrow, 1944; Meader and Darrow, 1947; Morrow, 1943). Although highbush blueberries (Vaccinium corymbosum L.) can be planted in large monoclonal blocks, yields obtained under these conditions may not be as great as those from mixed cultivar plantings (Hanson and Hancock, 1988). In rabbiteye blueberry (Vaccinium ashei), cross-pollination is particularly critical

Received for publication 11 May 2005. Accepted for publication 12 July 2005. The authors are greatly appreciative of the financial support provided by the Georgia Fruit and Vegetable Foundation. We also thank Blair Sampson for providing assistance with identification of bumblebee specimens and for his critical review of the manuscript. A contribution of the University of Georgia Agricultural Experiment Stations, Georgia Station, Griffin. This research was supported, in part, by state and Hatch Act funds allocated to the Georgia Agricultural Experiment Stations.

${ }^{1}$ Research associate.

${ }^{2}$ Professor. for adequate fruit set (El-Agamy et al., 1981). Therefore, interplanting two or more cultivars is recommended to facilitate outcrossing and improve yields.

Blueberries are pollinated by several species of bees (Hymenoptera: Apiformes), and these insects are expected to transfer pollen from one cultivar to another. The information available for blueberries, although scarce, suggests that bee-assisted pollen dispersion between cultivars may not be optimal. Vander Kloet and Lyrene plants in 2003 and 2004. ability of open 'Climax' flowers. abundance.
(1987) indicated that geitonogamous selfing (pollen transfer between flowers in the same plant) is likely to result as a consequence of the foraging behavior of blueberry pollinators. Moreover, Hancock etal. (1989) established that fruit size and seed number per berry declined with increasing distance from the source of cross-pollen.

One of the most important horticultural problems of the rabbiteye blueberry industry is poor fruit set (Scherm et al., 2001). Although knowledge of pollen dispersal is essential for maximizing cross-pollination and achieving optimal planting designs (Kron et al., 2001), pollen dispersion between rabbiteye cultivars has not been quantified previously. The objective of this research was to assess transport of cross-pollen by bumblebees in a rabbiteye blueberry planting.

\section{Materials and methods}

Study site. Experiments were conducted in 2003 and 2004 in a mixed 'Brightwell' and 'Climax' rabbiteye blueberry plot located at the Georgia Experiment Station in Griffin. The plot was $33 \times 29 \mathrm{~m}$ in size. Plants were spaced at $3.7 \mathrm{~m}$ across rows and $1.5 \mathrm{~m}$ within rows. 'Brightwell' and 'Climax' plants were arranged in alternating rows (i.e., 1:1 planting). The study site was isolated from other sources of blueberry pollen. The closest blueberry plantings were $>800$ m away.

Proportion of cross-pollen carried by bumblebees. Bumblebees (Bombus spp.) were chosen as a model species to study pollinator activity in blueberry plantings. The proportion of cross-pollen carried by bumblebees was used as an indirect measurement of pollen dispersion between 'Brightwell' and 'Climax' plants. Cross-pollen is defined here as 'Brightwell' pollen transported by bumblebees to 'Climax' plants, and vice versa. Frequency distributions of pollen tetrad diameter, measured with a particle counter, were used to predict the proportion of 'Brightwell' and 'Climax' pollen carried on the bodies of bumblebees. Brevis et al. (2005) described the technique and statisti-

Table 1. Number of bumblebees collected per sampling day from 'Brightwell' and 'Climax' blueberry

\begin{tabular}{|c|c|c|c|}
\hline \multirow[b]{2}{*}{ Sampling date } & \multicolumn{3}{|c|}{$\begin{array}{l}\text { Specimens collected } \\
\text { per cultivar (no.) }\end{array}$} \\
\hline & Brightwell & Climax & Total \\
\hline \multicolumn{4}{|l|}{$\overline{2003}$} \\
\hline 21 Mar. & 0 & 1 & 1 \\
\hline 23 Mar. & 0 & 8 & 8 \\
\hline 29 Mar. & 7 & 7 & 14 \\
\hline 2 Apr. & 10 & 5 & 15 \\
\hline 14 Apr. & 11 & $2^{z}$ & 13 \\
\hline Total & 28 & 23 & 51 \\
\hline \multicolumn{4}{|l|}{$2004^{y}$} \\
\hline 24 Mar. & 1 & 7 & 8 \\
\hline 27 Mar. & 8 & 8 & 16 \\
\hline 2 Apr. & 23 & 12 & 35 \\
\hline 5 Apr. & 23 & 13 & 36 \\
\hline 12 Apr. & 31 & $0^{2}$ & 31 \\
\hline Total & 86 & 40 & 126 \\
\hline
\end{tabular}

${ }^{2}$ Few or no specimens were collected on the last sampling day of each year due to the relatively low avail-

${ }^{y}$ Increasing numbers of bumblebees collected throughout the season reflect in part increasing pollinator 
cal analysis used in this study, so only a brief summary is given here. Tetrad diameter and number were analyzed with a Coulter counter (Multisizer II; Beckman Coulter, Fullerton, Calif.). Cultivar proportions in pollen mixtures carried by bumblebees were predicted using the maximum likelihood method. Essentially, this statistical analysis estimated the proportions of 'Brightwell' and 'Climax' pollen that would be necessary to obtain the frequency distributions of tetrad diameter observed in pollen mixtures extracted from the bodies of bumblebees.

Sampling of bumblebees. Naturally occurring bumblebeequeens were collected randomly from 'Brightwell' and 'Climax' plants. Bombus impatiens Cresson was the most abundant, but $B$. griseocollis (Degeer), B. bimaculatus Cresson and B. nevadensis auricomus (Robertson) were also collected. Adetailed description of the sampling procedure used in this study is given by Brevis et al. (2005). The total number of specimens collected in 2003 and 2004 was 51 and 126, respectively. Sample sizes per cultivar and date are shown in Table 1.

Flowering phenology. 'Climax' plants generally bloom earlier than 'Brightwell'(Krewerand NeSmith, 2000). To identify dates of cumulative $50 \%$ bloom and the period of maximum bloom overlap, flowering phenology data were collected at the study site in both years. Three stems were marked in each of 5 representative plants of each cultivar. Open flowers were counted in tagged stems at $1-$ to 3 -d intervals during the flowering season. Open flowers were removed after recording data, so that individual flowers could not be counted more than once. A nonlinear logistic model of the form $y=N /[N+(1$ $-N) \times \exp (-r \times t)]$ was fitted to the cumulative bloom data using NLIN procedure of SAS (SAS Institute, Cary, N.C.), where $y$ was cumulative bloom, $t$ was time in days, and $N$ and $r$ were parameters. The model gave a good fit to the data $(P<0.0001$ for each cultivar and year). Fitted models were used to determine dates of cumulative $50 \%$ bloom and to predict the daily percentage of open flowers. Curves of open flowers ( $\leq 5 \mathrm{~d}$ after anthesis) were simulated for 'Brightwell' and 'Climax' in 2004.

\section{Results}

The proportion of cross-pollen carried by bumblebees (mostly Bombus impatiens) visiting 'Brightwell' and 'Climax' plants in a mixed blueberry plot is summarized in Fig. 1. In 2003, proportions of cross-pollen from bumblebees collected in both cultivars followed the same distribution $\left(\chi^{2}=1.11\right.$; $\mathrm{df}$ $=1, P=0.29)$. About $75 \%$ of the specimens collected carried $<20 \%$ cross-pollen, and bumblebees with a 50:50 pollen mix from each cultivar were not found. In 2004, proportions of cross-pollen for specimens collected from 'Brightwell' and 'Climax' did not follow the same distribution $\left(\chi^{2}=11.80 ; \mathrm{df}=2, P \leq\right.$ $0.01)$. Most of the bumblebees collected from 'Brightwell' carried $<20 \%$ cross-pollen, while almost half of the catch from 'Climax' carried between $20 \%$ and $40 \%$ cross-pollen.

In 2004, cumulative $50 \%$ bloom for 'Brightwell' occurred $5 \mathrm{~d}$ later than for 'Climax' (3
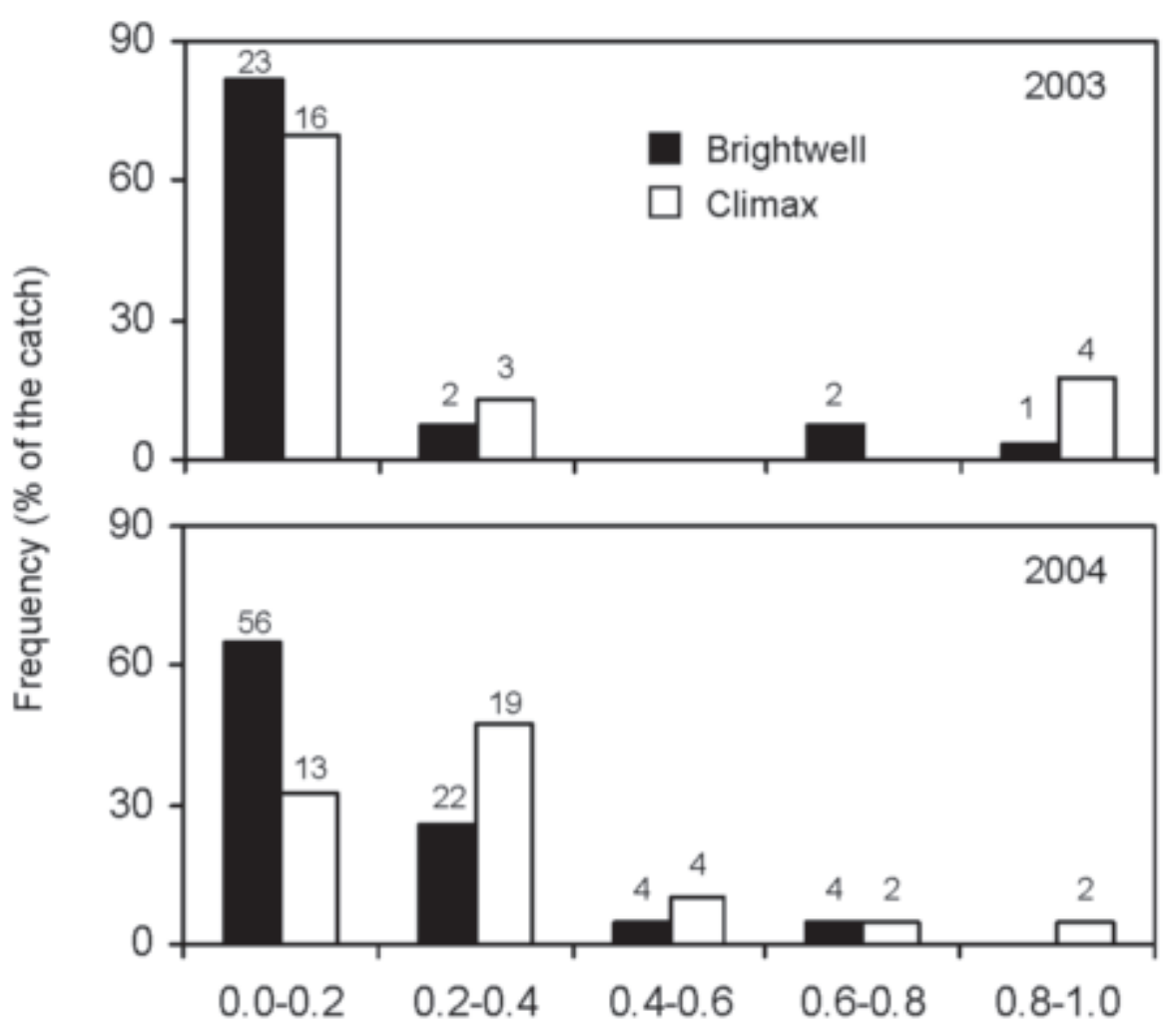

\section{Proportion of cross-pollen}

Fig. 1. Distributions of proportions of cross-pollen carried by bumblebees visiting 'Brightwell' and 'Climax' blueberry plants in a mixed rabbiteye blueberry plot in 2003 and 2004. Sample sizes (number of bumblebees collected) appear above each bar.
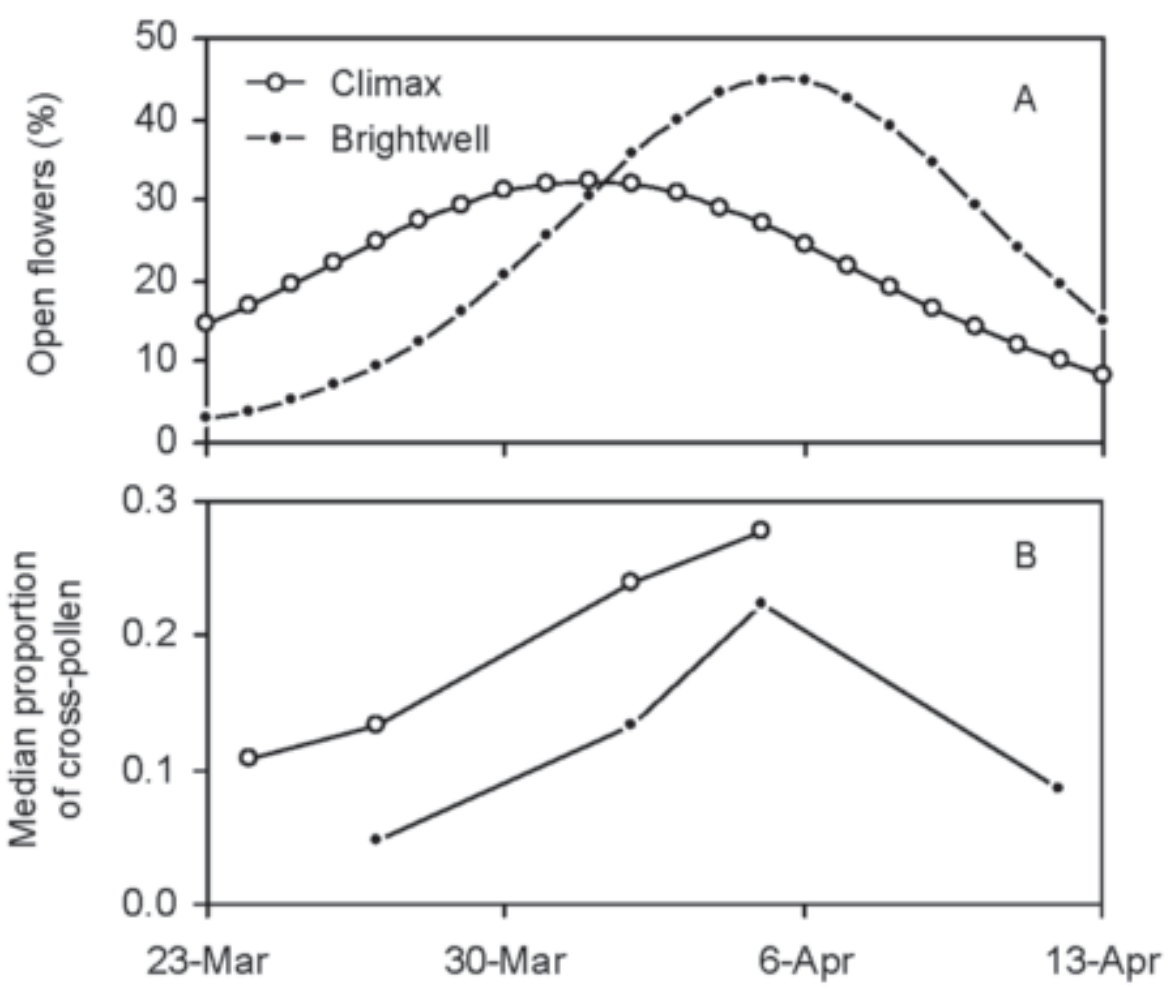

\section{Date}

Fig. 2. (A) Daily percentage of open flowers for each blueberry cultivar. The curves represent the predicted proportion of open flowers at stage $\leq 5 \mathrm{~d}$ after anthesis. (B) Median proportion of cross-pollen carried by bumblebees visiting 'Brightwell' and 'Climax' plants in a mixed blueberry plot. Both graphs show data from Spring 2004. 
Apr. and 29 Mar., respectively). The daily percentage of open bloom and the median proportion of cross-pollen carried by bumblebees collected from 'Climax' carried on average about $10 \%$ cross-pollen (that is, about $90 \%$ 'Climax' pollen). This was expected since 'Climax' was virtually the only cultivar with open flowers on that day. The proportion of cross-pollen carried by bumblebees foraging on 'Climax' increased as more open 'Brightwell' flowers became available. The highest likelihood for cross-pollination of 'Climax' flowers was recorded on $5 \mathrm{Apr}$. Specimens were not collected later than $5 \mathrm{Apr}$. on this cultivar because of the relatively low availability of open bloom.

Bumblebees collected from 'Brightwell' plants on 27 Mar. carried, on average, only 5\% cross-pollen. This was intriguing since there was a relatively high availability of 'Climax' flowers at the study site. The median proportion of cross-pollen for pollinators in 'Brightwell' followed the same pattern observed for those in 'Climax', and the maximum value was also recorded on 5 Apr. On the last sampling day, bumblebees visiting 'Brightwell' flowers carried about $10 \%$ cross-pollen. When sampling was done simultaneously in both cultivars (from 27 Mar. to 5 Apr.), bumblebees from 'Brightwell' always carried less cross-pollen than those from 'Climax'.

Bumblebees foraging on 'Brightwell' carried more blueberry tetrads on their bodies than those on 'Climax'. In 2004, the mean number of tetrads $( \pm \mathrm{SE})$ extracted per bumblebee was are shown in Fig. 2. On 24 Mar., bumblebees

$917 \pm 93$ and $539 \pm 49$ for specimens collected from 'Brightwell' and 'Climax', respectively (significantly different at $P<0.01$ ). These results confirmed the trend observed in 2003. The total number of tetrads and the proportion of 'Brightwell' pollen carried by bumblebees in 2004 were weakly but positively associated (Fig. 3). The association between the log-transformed number of tetrads and the proportion of 'Brightwell' was linear $(r=0.24$, $P \leq 0.01 ; \mathrm{n}=126)$.

\section{Discussion}

According to Shutak and Marucci (1966), fruit set levels as high as $80 \%$ are required for adequate commercial production of highbush blueberry. In rabbiteye blueberry, estimates as low as $8 \%$ to $10 \%$ have been recorded for the widely planted cultivar Tifblue (Lyrene and Crocker, 1983; NeSmith and Adair, 2004). Since fruit set responds positively to increased bee density (Dedej and Delaplane, 2003), it is generally thought that fruit set of rabbiteye blueberry is limited by insufficient pollen delivery to the stigmas. The results from the present study indicate that, in addition to insufficient pollen quantity, the source of the pollen deposited by pollinators could also play a role in determining fruit set under field conditions. Pollinators are likely to carry high proportions of self-pollen, and blueberry pistils do not have mechanisms to reject it (El-Agamy et al., 1982; Garvey and Lyrene, 1987; Krebs and Hancock, 1988; Vander Kloet, 1991). In cultivars with a low degree of self-fertility, deposition of pollen

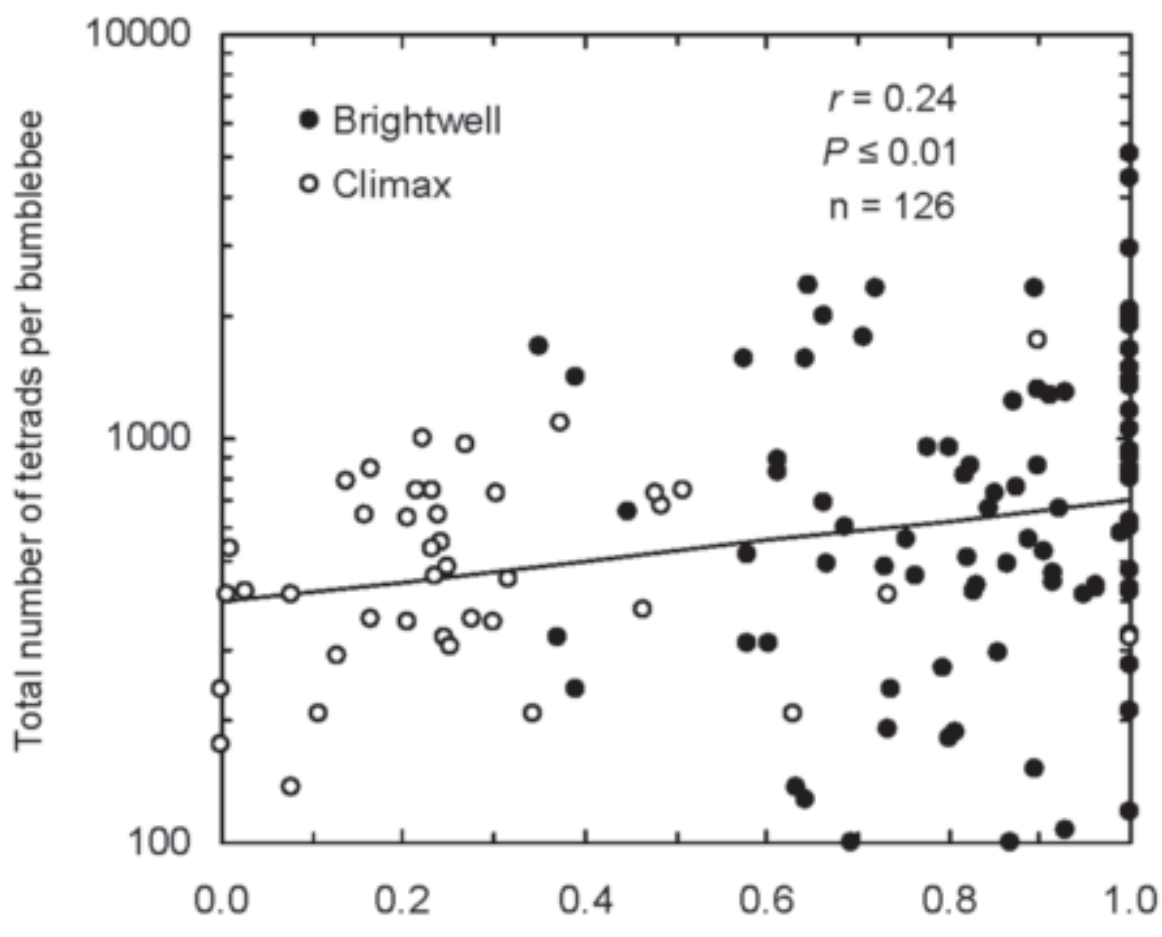

Proportion of Brightwell pollen on bumblebees

Fig. 3. Total number of tetrads and proportion of 'Brightwell' pollen carried by bumblebees visiting 'Brightwell' and 'Climax' blueberry plants in a mixed blueberry plot during Spring 2004. The line was fitted across untransformed data. Coefficient of correlation and significance level were estimated using the log-transformed number of tetrads per bumblebee. loads that are rich in self-pollen would represent a major limitation for fruit set. However, cultivars with a higher degree of self-fertility could still exhibit adequate fruit set under similar circumstances, even though fruit size and ripening rate may not be optimum. These findings indicate that breeding efforts should be made to select more self-fertile rabbiteye blueberry cultivars. Also, additional research is needed 1) to establish the effect of planting arrangements on pollen dispersion and 2) to determine if certain bee species carry more cross-pollen than others.

Bumblebees with a 50:50 pollen mix from each cultivar were rare in 2004 and absent in 2003. These results clearly indicate that bumblebees visited 'Brightwell' and 'Climax' flowers in a nonrandom fashion. Waser and Price (1983) reported that $90 \%$ or more of bumblebees' flower-to-flower flights are shorter than $1 \mathrm{~m}$. Low proportions of crosspollen carried by bumblebees at the study site might be explained by their tendency to visit many flowers within a plant (Vander Kloet and Lyrene, 1987) and to fly between adjacent monoclonal plants within the same row.

Proportions of cross-pollen carried by bumblebees changed during the flowering season. The greatest likelihood for cross-pollination occurred around the date of maximum bloom overlap. Therefore, the chances of cross-pollination at the study site were not only low, but were also limited to a narrow time window. The results from this study emphasize the need to maximize bloom overlap in blueberry plantings.

The low proportion of cross-pollen carried by bumblebees collected from 'Brightwell' early in the season was not consistent with the availability of open 'Climax' flowers. Selectivity toward virgin 'Brightwell' flowers could explain these results, although no data were collected to determine cultivar preferences by bumblebees.

Brevis and NeSmith (2004) established that 'Brightwell', on a per flower basis, releases more tetrads than 'Climax'. This difference seems to have an effect on bumblebee-assisted pollen carryover, and thus, on the extent of cross-pollination. Data from 2004 indicate that bumblebees harvested more tetrads from 'Brightwell' than from 'Climax'. Bumblebee foraging behavior is such that when they assess high pollen returns during a flower visit, both the frequency of grooming episodes and the handling duration per flower increase (Buchmann and Cane, 1989; Harder, 1990). Pollen carryover by pollinators during subsequent flower visits is thus restricted, because pollen is packed into scopae instead of being transported to the next flower. In concordance with this, bumblebees visiting 'Brightwell' flowers in 2004 carried lower proportions of cross-pollen relative to those collected from 'Climax'. The results from this study suggest that blueberry cultivars that release more pollen per flower can actually be exposed to a higher degree of selfing.

\section{Literature Cited}

Brevis, P.A. and D.S. NeSmith. 2004. Pollination discoveries on rabbiteye blueberries, p. 125-131. 
Proc. Ga. Fruit and Veg. Growers Conf. 9-10 Jan., Savannah.

Brevis, P.A., D.S. NeSmith, L. Seymour, and D.B. Hausman. 2005. Anovel method to quantify transport of self- and cross-pollen by bees in blueberry plantings. HortScience 40(7)2002-2006.

Buchmann, S.L. and J.H. Cane. 1989. Bees assess pollen returns while sonicating Solanum flowers. Oecologia 81:289-294.

Dedej, S. and K.S. Delaplane. 2003. Honey bee (Hymenoptera: Apidae) pollination of rabbiteye blueberry Vaccinium ashei var. 'Climax' is pollinator density-dependent. J. Econ. Entomol. 96:1215-1220.

El-Agamy, S.Z.A., W.B. Sherman, and P.M. Lyrene. 1981. Fruit set and seed number from self- and cross-pollinated highbush (4x) and rabbiteye (6x) blueberries. J. Amer. Soc. Hort. Sci. 106:443-445.

El-Agamy, S.Z.A., W.B. Sherman, and P.M. Lyrene. 1982. Pollen incompatibility in blueberries ( $\mathrm{Vac}$ cinium spp.). J. Palynol. 18:103-112.

Garvey, E.J. and P.M. Lyrene. 1987. Self incompatibility in 19 native blueberry selections. J. Amer. Soc. Hort. Sci. 112:856-858

Hancock, J.F, S.L. Krebs, M. Sakin, and T.P. Holtsford. 1989. Increasing blueberry yields through mixed variety plantings. Mich. State Hort. Soc. Annu. Rpt. 119:130-133.

Hanson, E.J., and J.F. Hancock. 1988. Hints on growing blueberries. Mich. State Univ. Ext. Bul. E-2066.

Harder, L.D. 1990. Behavioral responses by bumble bees to variation in pollen availability. Oecologia 85:41-47.

Klekowski, Jr., E.J. 1988. Mutation, development, selection, and plant evolution. Columbia Univ. Press, New York.

Krebs, S.L. and J.F. Hancock. 1988. The consequences of inbreeding on fertility in Vaccinium corymbosum L. J. Amer. Soc. Hort. Sci.113:914-918.

Krewer, G. and D.S. NeSmith. 2000. Blueberry cultivars for Georgia. Univ. Ga. Fruit Publ. 00-2. 25 Mar. 2005. http://www.smallfruits.org/Blueberries/production/BlueberryCultiv.htm.

Kron, P., B.C. Husband, P.G. Kevan, and S. Belaoussoff. 2001. Factors affecting pollen dispersal in high-density apple orchards. HortScience 36:1039-1046.

Lyrene, P.M. and T.E. Crocker. 1983. Poor fruit set on rabbiteye blueberries after mild winters: Possible causes and remedies. Proc. Fla. State Hort. Soc. 96:195-197.

Meader, E.M. and G.M. Darrow. 1944. Pollination of the rabbiteye blueberry and related species. Proc. Amer. Soc. Hort. Sci. 45:267-274.

Meader, E.M. and G.M. Darrow. 1947. Highbush blueberry pollination experiments. Proc. Amer. Soc. Hort. Sci. 49:196-204.

Morrow, E.B. 1943. Some effects of cross-pollination versus self-pollination in the cultivated blueberry. Proc. Amer. Soc. Hort. Sci. 42:469-472.

NeSmith, D.S. and H.M. Adair. 2004. Rabbiteye blueberry field trials with the growth regulator CPPU. Small Fruits Rev. 3(1/2):183-191.

De Nettancourt, D. 1977. Incompatibility in angiosperms. Springer, Berlin.

Scherm, H., D.S. NeSmith, D.L. Horton, and G. Krewer. 2001. A survey of horticultural and pest management practices of the Georgia blueberry industry. Small Fruits Rev. 1:17-28.

Seavey, S.R. and K.S. Bawa. 1986. Late-acting self-incompatibility in angiosperms. Bot. Rev. 52:195-219.

Shutak, V.G. and P.E. Marucci. 1966. Plant and fruit development, p. 179-198. In: P. Eck and N.F. Childers (eds.). Blueberry culture. Rutgers Univ. Press, New Brunswick, N.J.

Vander Kloet, S.P. 1991. The consequences of mixed pollination on seed set in Vaccinium corymbosum. Can. J. Bot. 69:2448-2454.

Vander Kloet, S.P. and P.M. Lyrene. 1987. Self-incompatibility in diploid, tetraploid, and hexaploid $\mathrm{Vac}$ cinium corymbosum. Can. J. Bot. 65:660-665.

Waser, N.M. and M.V. Price. 1983. Optimal and actual outcrossing in plants, and the nature of plant-pollinator interaction, p. 341-359. In: C.E. Jones and R.J. Little (eds.). Handbook of experimental pollination biology. Van Nostrand Reinhold, New York. 